\title{
SISTEMA DE ALMACENAMIENTO EN EL VALLE MEDIO DE CAÑETEY SU IMPORTANCIA PARA EL MANTENIMIENTO DEL ESTADO INKA
}

\author{
FAVIO RaMíREZ MuÑoZ* \\ Museo Municipal del Distrito de CERro AZul \\ favramirez@gmail.com
}

\section{RESUMEN}

El presente artículo muestra los resultados del «Proyecto de Investigación Arqueológica Pacarán 01» que fue concebido ante la necesidad de contribuir al conocimiento de la organización social durante la ocupación Inka en el valle medio de Cañete, pretendiendo aportar en el discernimiento de las relaciones entre las sociedades y los entornos geográficos. Para dicho propósito se optó por intervenir el sitio arqueológico denominado Pacarán 01, también conocido como «Colcas de San Marcos».

Palabras Clave: Arquitectura Inka, Estado Inka, Sistema de Almacenamiento, Medios Auxiliares de Almacenaje, Estudios Botánicos, Valle de Cañete, Aprovechamiento de Recursos.

\section{AbSTRACT}

The present article shows the results of the «Archaeological Research Project Pacarán 01» that was conceived from the need to contribute to the understanding of social organization during the Inca occupation in the middle valley of Cañete, pretending to bring in discerning relationships between societies and geographical environments. For this purpose we chose to intervene archaeological site called Pacarán 01, also known as «San Marcos Colcas».

KeYwords: Architecture Inka, Inka State, Storage System, Storage Auxiliary Means of, botanical studies, Cañete Valley, Resource Utilization.

\section{INTRODUCCIÓN}

La mayoría de los estudios arqueológicos del valle de Cañete se centran en la sección del valle bajo, donde se han realizado algunas investigaciones con excavaciones sistemáticas (Kroeber 1937; Marcus 1985; Ruales 2000), todas ellas referidas a asentamientos con arquitectura monumental. El resto de investigaciones del valle bajo están basados en prospecciones realizadas por algunos arqueólogos como parte de estudios particulares, no conformando programas de investigación a largo plazo propiamente dicho, estos se han basado mayormente en la descripción arquitectónica de las estructuras

* Licenciado en arqueología, egresado de la Universidad Nacional Mayor de San Marcos. Director del Museo Municipal del Distrito de Cerro Azul. 
visibles en los sitios más importantes que han sido descritos desde inicios del siglo pasado por algunos viajeros europeos y en algunos casos se ha buscado su asociación con insuficientes fragmentos de cerámica de superficie.

Para el valle medio de Cañete hasta el momento anterior a nuestra excavación no se había realizado ninguna investigación con excavaciones sistemáticas; al igual que en el valle bajo la mayoría de artículos se centraba en la descripción arquitectónica realizada durante algunos días de prospección, sin necesidad de formar parte de proyectos de investigación y en algunos casos solo se centran en confirmar lo que se sabía por medio de las crónicas (Vega-Centeno 2011); sin embargo, existen dos trabajos loables realizados en este sector del valle, ambos basados en prospecciones y estudios detallados con metodologías definidas y que formaron parte de proyectos de investigación sin excavaciones, estos son los trabajos realizados por John Hyslop durante las décadas de 1970 y 1980 en el cual identificas algunos caminos utilizados en época incaica y también un análisis arquitectónico del sitio de Incawasi del cual realiza un registro detallado de todo el complejo tratando de definir las posibles funciones de los sectores que la conforman; el otro caso de estudios detallados son los trabajos realizados por el Proyecto Qhapaq Ñan del Ministerio de Cultura, que identifican muchos de los sitios tardíos del valle medio y su asociación a tramos del camino Inka, aportando, incluso para el caso de los caminos prehispánicos, una metodología para el estudio de los mismos (Casaverde y López 2011).

De lo mencionado podemos aseverar que no había trabajos relacionados al estudio arquitectónico de depósitos en el valle medio de Cañete y tampoco existían estudios relacionados a la identificación de las especies botánicas cultivadas en dicha zona de estudio, siendo nuestro proyecto de investigación el primero en tocar dichos temas en el valle medio, con lo cual se espera aportar nuevos datos para la comprensión de la sociedad que ocupó el valle medio durante la anexión al incanato y entender la correlación entre el medio ambiente y el desarrollo social prehispánico tardío en cuanto a aprovechamiento de recursos y complejización social.

Cabe indicar que los depósitos hasta ahora estudiados en otros lugares del Perú por diferentes autores (Morris 1973; Matos 1994; Huaycochea 1994; Protzen 2008; Topic: 1992) siempre están referidos a depósitos ubicados en las serranías y asociados a ciudades incaicas importantes o cabezas de provincia (Huanucopampa, Pumpu, Ollantaytambo), siendo el único estudio de recintos de almacenamiento en la costa el trabajo de Duccio Bonavía en Los Gavilanes; sin embargo este último está referido a una época precerámica y no al lapso cronológico al que se refiere nuestro tema de estudio. Por lo tanto, podemos afirmar que nuestro trabajo sería el pionero en describir las características arquitectónicas de un sitio ubicado en un valle costero que cumple la función de acopio en favor de las actividades estatales incaicas, y al mismo tiempo busca identificar las especies botánicas aprovechadas por dicha sociedad (tanto para el consumo alimenticio como para la construcción de edificios) en el valle medio de Cañete, para desde este punto plantear algunos alcances hacia las zonas que presenten características geográficas parecidas a la de nuestro espacio de estudio referido.

\section{DESCRIPCIÓN GEOGRÁFICA DE LA ZONA DE ESTUDIO}

El valle medio del río Cañete es un sector que abarca los distritos de Nuevo Imperial, Lunahuaná, Pacarán y Zúñiga por parte de la provincia de Cañete, y los distritos de Chocos, Putinza y Catahuasi por parte de la provincia de Yauyos. Cabe destacar que algunos autores consideran como valle medio solo el espacio entre Lunahuaná y Pacarán; sin embargo el autor del presente artículo ha recorrido todo el valle y reconoce como valle medio todo el espacio antes mencionado ya que en toda esa zona se comparte las mismas características geográficas.

El valle medio es largo pero estrecho, conformado por una sucesión de cerros arcillosos y cerros rocosos con taludes que contienen piedras sueltas y abundante cascajo debido al desgaste de la misma roca firme; en sus conos de deyección se observan continuos deslizamientos aluviónicos que ocurren 
en las temporadas de verano, que incluso han afectado varios sitios arqueológicos. Esta zona es de clima muy seco y semi-cálido, siendo su precipitación pluvial concentrada entre los meses de enero a marzo; la tierra es aprovechada para el cultivo de diversos productos, para lo cual se utilizan canales de regadío que toman sus aguas del mismo río, algunos de estos canales son de origen prehispánicos y otros corresponden a las ampliaciones de los mismos, realizado por los actuales pobladores.

Los suelos del valle medio de Cañete pueden clasificarse en cuatro tipos. El orden en el que se redactan corresponde al porcentaje en que se muestran en dicho espacio. El primero son los suelos arcillosos, formados principalmente por arcilla, de granos muy finos y color amarillo claro con tonalidades blancas, retienen el agua formando charcos; si se mezclan con humus pueden ser buenos para cultivar. El segundo son los suelos humíferos, que en su composición abunda la materia orgánica en descomposición, son de color oscuro, retienen bien el agua y son buenos para el cultivo. El tercero son los suelos pedregosos, formados por rocas de todos los tamaños. No retienen el agua y no son buenos para el cultivo. El cuarto son los suelos arenosos, formados principalmente por arena, son suelos que no retienen agua y no son muy aptos para la agricultura.

Entre las plantas oriundas del Perú que crecen de manera silvestre desde tiempos inmemoriales en esta zona del valle podemos citar al molle, la caña brava, el pájaro bobo y el sauce, los cuales fueron aprovechados por las sociedades prehispánicas en diversas actividades. Además luego de la llegada de los españoles se insertaron en el valle muchos sembríos foráneos que hasta el día de hoy se cultivan debido a las características geográficas que permiten una buena producción de dichas especies, entre ellas podemos citar la manzana, el níspero, la uva y el higo. Estas han permitido el desarrollo económico agropecuario de sus pobladores que combinan dichos cultivos con la producción de híbridos de maíz y algodón.

En este marco geográfico hallamos al sitio arqueológico Pacarán 01 ubicado dentro del anexo de San Marcos, nombre que adoptó después de la desaparición de la Hacienda San Marcos en dichos terrenos. Este a su vez pertenece al distrito de Pacarán, el cual conforma uno de los dieciséis distritos de la provincia de Cañete, en la región Lima Provincias, departamento de Lima. El distrito de Pacarán colinda con los distritos de Lunahuaná y Zúñiga, y se caracteriza por ser un pueblo de campesinos de gran producción vitivinícola y maíz morado. Es uno de los pueblos con poca presencia turística, a pesar de su cercanía con el distrito de Lunahuaná, lo cual lo hace un pueblo conservador de sus costumbres y folklor. Tiene una Iglesia Colonial en buen estado de conservación y muchos de los sitios arqueológicos con arquitectura corresponden a la época Inka, también existen petroglifos cercanos a la orilla del río que corresponden a épocas más tempranas.

\section{ANTECEDENTES DE LA ZONA DE ESTUdio}

En el año 1974 aparece la publicación de los arquitectos Carlos Williams y Manuel Merino referido al inventario de los sitios arqueológicos del valle medio y bajo de Cañete realizado por encargo del INC. Durante este trabajo se identificaron en el valle medio de Cañete 15 sitios arqueológicos que contienen importantes recintos identificados como colcas, ubicados entre los distritos de Lunahuaná y Pacarán, entre ellos los más resaltantes son Inkawasi, Colcas de San Marcos (Pacarán 01), Colcas de Huanaco, Colcas de Higuerón, Uchupampa, Condoray y Peña de la Cruz de San Juan. En dicho trabajo Williams y Merino presentan algunos dibujos a mano alzada de las mencionadas colcas, las cuales durante nuestras prospecciones hemos logrado identificar varias faltas en aquellos gráficos, por ejemplo planos incompletos, diseños erróneos de las plantas y la presentación de construcciones modernas como si fueran parte de las estructuras arqueológicas. Suponemos que estas equivocaciones se deben a la realización de los dibujos tomando como base las fotografías aéreas.

En el año 1984 John Hyslop publica The Inca Road System, obra basada en sus prospecciones de 1979 por el valle de Cañete cuyo objetivo fue definir caminos incaicos dentro de este valle costero. El autor señala la existencia de dos caminos principales en el valle de Cañete, uno que corre por la 
costa y el otro que se dirige hacia valle adentro. El primero de estos caminos partió desde Tampu Inka en la margen sur del valle de Asia y pasó por casi $35 \mathrm{~km}$ de arena hasta llegar al principal sitio Inka de Cerro Azul, probablemente este sector de camino nunca fue una entidad formalmente construida sino más bien solo fue una senda en el desierto, marcado por postes de madera. Desde Cerro Azul una ruta procedió tierra adentro pasando por Cerro del Oro hasta Ungará, desde donde se podía viajar hacia el sur hasta Chincha o tierra adentro en las montañas. La segunda ruta procedió a lo largo de la costa marina pasando por Vilcahuasi y arribando al importante sitio Inka de Herbay Bajo, desde el cual se podía seguir hacia el gran centro Inka denominado Complejo Centinela en Chincha. El segundo camino de importancia que cita el autor es el que se observa en el valle medio de Cañete y que posiblemente llegaba desde la costa hasta Jauja. Este camino se observa en algunos sectores del valle medio y consta de un muro de un solo paramento adosado a la roca firme del cerro formando en su cabecera un estrecho espacio plano de camino, el que estaría directamente asociado a los sitios Inka de Toma, Escalón e Inkawasi.

En el año 1985 John Hyslop publica Inkawasi. The New Cuzco, basado en el análisis arquitectónico y cerámico de los elementos vistos en superficie en el complejo arqueológico de Inkawasi, durante este trabajo dividió el sitio en ocho sectores (A-H) tomando en cuenta las características arquitectónicas. De esta manera el autor señala que el sector A parece ser una enorme área de almacenamiento con una plataforma central para dirigir la distribución de las mercancías que ingresaban o salían. El sector B posiblemente tuvo una función residencial. El sector C se plantea como el Templo del Sol, con una plaza trapezoidal para las ceremonias, un área funeraria y grandes corrales para llamas. El sector D se trataría de un área para la residencia de personas que no tenían un status de élite; esto debido a la presencia de cuartos aglutinados algo asimétricos, frecuente presencia de poyos y una gran cantidad de alfarería no decorada y sin engobe. El sector E correspondería a un área ceremonial, con recintos para funciones laborales y residenciales, y una gran plaza con un ushnu para actividades simbólicas. $\mathrm{El}$ sector $\mathrm{F}$ al parecer sería un aqllawasi. El sector $\mathrm{G}$ se identificaría como un medio de almacenaje por sus unidades cuadrangulares, aunque las remodelaciones podrían indicar que posteriormente se dieron otras actividades. El sector H probablemente sirvió como puesto de observación para el tráfico a lo largo del río.

En el libro Ciudad y territorio en los Andes (2009) José Canziani describe someramente el asentamiento de Inkawasi (en Lunahuaná) enfatizando que el sector A fue el centro de almacenamiento, el cual presenta una planta cuadrangular con un solo ingreso y en sus lados este, sur y oeste presentan de 3 a 4 hileras de cubículos cuadrangulares que posiblemente correspondían a almacenes techados a los que se accedía desde arriba. Estos depósitos rodean el área central que presenta 42 compartimientos rectangulares que al parecer habrían servido como tendales para preparar, secar, acomodar y contabilizar los productos que ingresaban o se despachaban desde los depósitos. En el centro de este complejo se construyó una plataforma rectangular que podría haber servido como lugar de instalación de los funcionarios a cargo de la administración del movimiento de bienes. El sector E está dominado por una gran plaza abierta de forma trapezoidal; compartiendo los ejes del trazado de la plaza se desarrolla un gran complejo de planta trapezoidal que tiene cerca de 96 recintos, dividido en dos subsectores separados por un corredor; el subsector este presenta grandes recintos rectangulares mientras que el subsector oeste presenta 7 hileras de recintos de menor tamaño separados por corredores paralelos. Para Canziani los sectores «A» $\mathrm{y}$ «E» corresponden a un sistema diversificado de almacenamiento, donde el sector A almacenaría productos alimenticios mientras que el sector $\mathrm{E}$ podría estar destinado al depósito de armas y vestimenta necesaria para la gente de guerra.

En la revista Haucaypata 3 (2011) aparece un artículo de Patricia Vega-Centeno que trata sobre los sitios arqueológicos del distrito de Pacarán. La autora plantea el objetivo de comprender la organización de una supuesta huaranga de Pacarán que formaría parte del señorío de Lunahuaná, para lo cual parte de la premisa señalada por María Rostworowski quien señala que el mencionado señorío estuvo 
formado por cuatro huarangas. Este artículo tiene varios puntos criticables por cualquier investigador que haya prospectado la zona de estudio, en primer lugar sus planos no coinciden con la realidad, mostrando para el caso de Guanaco 1 y Huagil gráficos solamente de pequeños sectores de las edificaciones, confundiéndolas como si se trataran del asentamiento en total. Según Vega-Centeno el sitio arqueológico de San Marcos corresponde a la residencia de un «curaca» con depósitos ubicados en la ladera del cerro, Huaca Daris es referida como un posible Acllahuasi; sin embargo no señala las características arquitectónicas que sustente lo señalado. Además opina que Huagil tiene todas las características de un tambo de acopio, pero no señala cuales son los recintos de descanso y mucho menos se observa en su plano recintos de acopio, lo cual es necesario en cualquier sitio identificado como tambo.

\section{ANTECEDENTES DEL TEMA DE ESTUdio}

En 1981 Craig Morris publica algunos alcances sobre la subsistencia y el tipo de almacenamiento llevado a cabo en una importante cabeza de provincia Inka. La excavación de Morris de una muestra de 95 colcas en Huanuco Pampa tuvo como propósito la determinación de los bienes almacenados, los métodos de almacenamiento, el hallazgo de rasgos arquitectónicos asociados a los almacenes y la tecnología de almacenamiento. El autor señala que en las colcas excavadas el almacenamiento del maíz, al menos en la forma desgranada guardada en cántaros, parece estar limitada a las estructuras circulares, identificando solo productos de raíces en las colcas rectangulares; sin embargo Morris resalta que debido a lo pequeño de su muestra no puede concluir que los almacenes rectangulares sean exclusivamente para tubérculos.

En 1982 Duccio Bonavía escribe acerca de sus investigaciones en el sitio arqueológico Los Gavilanes ubicado en la costa de Huarmey; en esta zona el autor halló 47 estructuras identificadas como depósitos, los cuales consistían en pozas cavadas en la arena de forma troncocónica y con sus perfiles cubiertos de piedras de la zona, estos depósitos eran utilizados para el almacenamiento del maíz en el Precerámico final, hace unos 4000 años atrás y afirma que se trata de un verdadero sistema que permitía almacenar ingentes cantidades de granos de maíz. Referente a la forma de almacenamiento se presume que el maíz era depositado mezclándose con arena para evitar la presencia de insectos y enfermedades, para así facilitar su conservación.

En 1992 aparece un artículo de John Topic y Coreen Chriswell quienes realizaron excavaciones en los recintos de almacenamiento Inka de Huamachuco ubicados en los cerros Santa Bárbara, Mamorco y Cacañan. En el cerro Santa Bárbara al parecer se construyeron aproximadamente 125 depósitos, asentados sobre cinco terrazas, las estructuras miden 5 x $4 \mathrm{~m}$, con eje longitudinal siempre orientado a lo largo del contorno del cerro. En 1982 los autores citados excavaron cuatro cortes a lo largo de cuatro colcas, el corte 1 produjo una pequeña cantidad de carbón de lo que parecería ser un entablado, los cortes 3 y 4 produjeron maíz carbonizado. En el cerro Mamorco hay tres grupos de colcas, la primera presenta 19 recintos en una sola fila, la segunda tuvo algo de 15 y la tercera tienes dos grupos de colcas dispuestas en forma de «V» que convergen en el lado norte; estas estructuras miden aproximadamente 8 x 3,5 m. En 1983 los autores excavaron parcialmente tres colcas continuas, lo cual mostró que las colcas «A» $\mathrm{y}$ «B» tenían canales subterráneos con los lados revestidos por lajas de piedras y el fondo conformado por la misma roca firme. Todos los canales al parecer atravesaron los muros en ambos lados. En la excavación de la colca «C» se hallaron fragmentos de argamasa marcada con caña, las cuales fueron consideradas como evidencia de un techo terminado, en este recinto también se halló un posible artefacto que consiste en un trozo de cal que posiblemente era usado durante el almacenamiento ya que la información etnográfica les indicaba que la cal es rociada a las plantas de papa para prevenir alguna plaga y a veces es rociada entre las papas almacenadas para protegerlas de los insectos e infecciones funginas. En el cerro Cacañan aparece un grupo de colcas en una sola hilera sobre una terraza con recintos separados por un espacio entre 4 a 5 m. En 1983 los autores excavaron 
completamente dos colcas y parte de uno de los edificios más grandes, lo cual mostró la construcción de canales subterráneos que al parecer estaban descubiertos al exterior en ambos lados, estos pudieron ser usados para aumentar la humedad dentro de la estructura, así como también en el drenaje en caso de exceso de agua.

En 1994 se publica un artículo de Ramiro Matos referido al estudio de colcas del centro administrativo Inka de Pumpu ubicado en la puna de Junín. El autor indica que los sitios Inka de la puna de Junín tienen siempre colcas como su componente principal, o simplemente son sitios de colcas instalados en lugares estratégicos para recepcionar los productos durante la cosecha. Gran parte de su investigación se centra en las colcas del cerro Shongoymarca y las colcas de la Pampa excavando pequeños sondeos de prueba. Señala que las colcas de Shongoymarca están aisladas del pueblo, conformadas por depósitos cuadrangulares, rectangulares y circulares, siendo las ortogonales las instalaciones principales. También observa que en el extremo sur se ubican estructuras con compartimientos múltiples que podrían ser las habitaciones de los colcamayoc. En cambio las colcas de la Pampa son circulares y ordenadas en hileras y están vinculadas a las viviendas de la población. En ambos casos se identificó elementos comunes asociados a las colcas, por ejemplo pisos en terrazas, espacios abiertos y delimitados a grupos de colcas, patios cerrados por grupos de colcas, colcas diferenciadas por corchetes y su ordenamiento en hileras. El autor también señala la existencia de colcas particulares o familiares, directamente asociada a las viviendas del barrio de los comuneros, se trata de pequeños silos subterráneos de un promedio de $0.80 \mathrm{~m}$ de diámetro y $1 \mathrm{~m}$ de profundidad, de piso adoquinado con lajas de piedras y paredes en corte cilíndrico apoyando el reverso al corte del suelo.

En 1994 Flor de María Huaycochea publica un libro basado en el estudio del sistema de almacenamiento en la zona del Cusco. La autora toma un muestreo de colcas procedente de tres sitios arqueológicos diferentes en el distrito de Ollantaytambo. Las Qolqas de Peñas tienen una estructura simple de planta rectangular, cada uno de estos depósitos presenta un vano superior en el lado oeste para la ventilación y al mismo tiempo para el llenado del recinto, un vano inferior para la ventilación y un ducto o canal para la refrigeración y drenaje. Las Qolqas de Pumamarca tienen una estructura simple, de planta rectangular con las esquinas externas en ángulo recto y las internas redondeadas, cada uno de estos depósitos presenta un vano superior de forma trapezoidal para ventilación y llenado del producto, vanos laterales superiores para la ventilación cruzada, un vano inferior de forma trapezoidal para ventilación del piso y un ducto de drenaje o canal para refrigeración. Las Qolqas de Incarakay se dividen en dos grupos, la primera, de planta rectangular y conformada por un solo ambiente, mientras que la segunda mantiene las mismas características de planta, pero con tres vanos en la parte inferior.

En el 2008 Jean Pierre Protzen ejecuta estudios de colcas en Ollantaytambo, señalando que los depósitos en esta zona pueden clasificarse en dos tipos, el Tipo 1 consiste de dos a cuatro cámaras rectangulares construidas de manera contigua, cada una con su propio acceso mediante una pequeña abertura cuadrada cerca del suelo. El Tipo 2 está conformado por estructuras rectangulares con el muro frontal ubicado ladera abajo siendo más bajo que el muro posterior ubicado ladera arriba lo cual da como resultado un techo a dos aguas, asimétrico y empinado; por lo general el acceso a estos recintos es mediante entradas en uno o ambos muros cortos del rectángulo. El autor señala algunas variaciones en el diseño del tipo 1, por ejemplo en algunos recintos del cerro Pinkuylluna aparece un drenaje o ducto de ventilación que corre a lo largo de la estructura, en el cerro Bandolista algunos recintos presentan sus cámaras separadas unas de otras por espacios entre 20 a $30 \mathrm{~cm}$ de ancho y la parte superior de estos parece haber estado cubierta con lajas, en el cerro Piri las dos cámaras centrales son contiguas y las dos exteriores están separadas mediante espacios, en Vista Alegre los muros inferiores servían también como entradas ya que no tienen entradas en los hastiales.

En el 2010 la revista Arqueología y Sociedad publica un artículo de Sofía Chacaltana referido a un Tambo Inca en el valle alto de Moquegua llamado Camata Tambo, el cual presenta 31 cuartos de acopio 
y una capacidad promedio de almacenamiento de aproximadamente $700 \mathrm{~m}^{3}$. Estos recintos presentan paredes rectangulares y pequeñas ventanas en la parte de la fachada, también presentan piedras planas que sobresalen en las paredes formando una línea diagonal que posiblemente fue utilizado como escalera para ingresar a los almacenes por la parte superior. La excavación de algunos depósitos de Camata Tambo, Camata Cullpas y Camata Pueblo a través de estudios macrobotánicos y análisis de polen mostró presencia de ají, maíz, papa, berenjena, tomate, frejol, molle, chirimoya, pacae, pepino y capulí. El mencionado estudio de polen mostraría que algunas de estas plantas no fueron cosechadas en la zona y que posiblemente procederían del valle medio o bajo de Moquegua.

\section{Descripción ARQuitectónica del Sitio ARQueológico PaCARÁn 01}

El sitio arqueológico está conformado por dos espacios con diferentes funciones por lo cual se consideró dividir la edificación en dos sectores, el sector A es la zona identificada como recintos para depósitos de productos asociado a áreas de secano, al cual hemos denominado «Área de almacenamiento» y el sector B es la zona identificada como espacios para el descanso del personal encargado del mantenimiento de las colcas, al cual hemos denominado «Área habitacional». Todo el conjunto arquitectónico está conformado por piedras cortadas de la misma roca firme sobre la cual se asienta, y unidas con argamasa de arcilla limosa de la sección baja del cerro, esta es la misma arcilla que hasta la actualidad los pobladores cercanos al sitio utilizan para la construcción de corrales y viviendas. (Fig. 1).

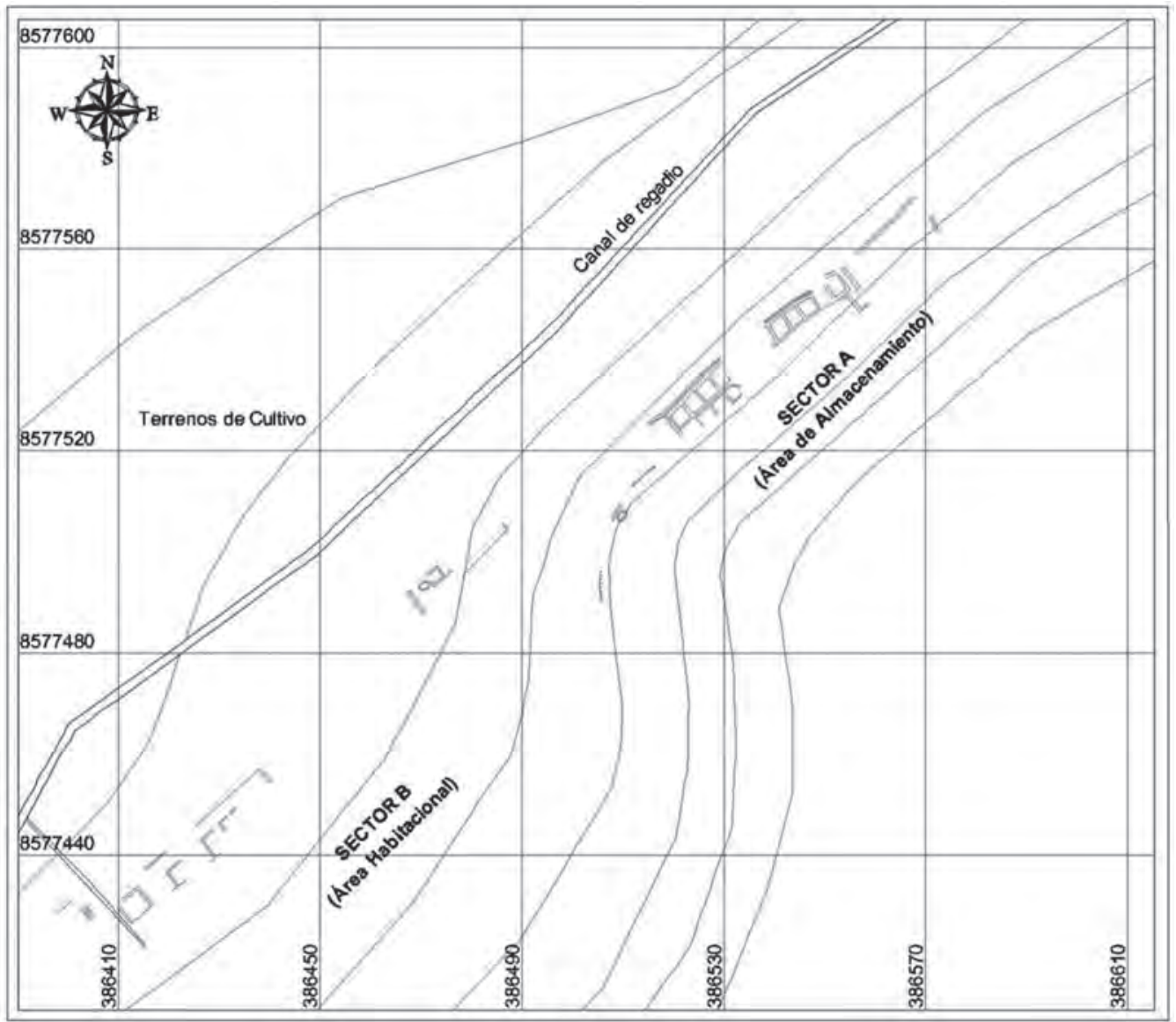

Figura 1. Sectorización del sitio arqueológico. 
El sector A se ubica en la ladera media del cerro Huanaco, sobre una superficie fuertemente pronunciada, en un terreno nada propicio para la agricultura ya que en este espacio el cerro está conformado por la roca firme y un talud de cascajo, gravas y piedras angulosas. Está compuesta por dos conjuntos arquitectónicos (1A y 2A) adjuntos uno al lado del otro, orientados hacia al noroeste, los cuales guardan el patrón ortogonal típico de las características constructivas incaicas en el valle medio de Cañete. En todo el paramento exterior del muro de fachada se observan las huellas de los dedos de los albañiles que realizaron el revoque. Otro aspecto a resaltar es la presencia de pequeños muros de contención en el talud del cerro que aparecen tanto en la parte superior como en la inferior de la edificación y al parecer tendrían la función de evitar deslizamientos del talud.

El conjunto $1 \mathrm{~A}$ fue el espacio intervenido en esta temporada de investigación. Está conformada por dos filas de recintos de planta cuadrangular asentadas sobre una plataforma a desnivel, siendo la primera fila la de mayor altura. Al lado noreste de estos recintos aparece un espacio rectangular delimitado en la sección anterior por la prolongación del muro de fachada del edificio y en la sección posterior por la misma roca firme que conforma el cerro. Este espacio rectangular pudo servir para la preparación, secado, clasificación y conteo de los productos antes de su ingreso a los recintos así como también al momento de salida de los mismos. La primera fila de depósitos está conformada por dos recintos cuadrangulares y un recinto semicircular adjuntos a la roca firme (1, 2 y 3); estos recintos están cubiertos por el deslizamiento del talud del cerro. La segunda fila de depósitos aparece en un nivel relativamente inferior en relación a la anterior, en ella se observan cuatro recintos $(4,5,6$ y 7$)$ de los cuales tres están totalmente definidos mientras el recinto 4 solo presenta la base del depósito, el cual al parecer forma parte de una remodelación en el edificio en una segunda fase constructiva. En uno de los paramentos del recinto 6 se observan cinco aberturas que forman una línea en diagonal, llegando desde la base del depósito hasta la cabecera del muro, lo cual hemos identificado como oquedades en las que se insertaban lajas de piedras que servían como una escalinata pegada al muro desde la cual podían acceder al interior del recinto desde la cabecera de los dos muros ejes del conjunto 1A, esta escalinata en voladizo nos permite proponer que los recintos no eran totalmente cerrados y que por el contrario contaban con un espacio abierto para la ventilación de los productos o por lo menos con un espacio de cubierta móvil, el mismo que posiblemente no fue muy amplio y solo formaba un pequeño cuadrado en la cubierta del recinto, lo suficiente para el ingreso de una persona que logre acomodar las vasijas o costales en el interior del depósito. El recinto 7 al parecer es construido en una fase posterior, observándose que la construcción de la fachada se adosa a la del recinto 6 y no es una prolongación en un solo momento. Toda la fachada en este sector presenta dos muros arriostrados de alturas menores, estos sirven para brindar un mayor soporte o refuerzo a las bases de la fachada y de esta manera evitar el deslizamiento de los muros que soportan cargas internas. Al lado del recinto 7 se adjunta otro muro portante que le sirve de ayuda al soporte de cargas internas; sobre la cabecera de dicho muro portante se asienta una prolongación en su alzada, elaborada con piedras de menor tamaño, dispersas de manera desordenada y unidas con abundante argamasa de arcilla limosa. Esta al parecer no se trata de otra fase constructiva sino que corresponde a un segundo momento constructivo dentro de la primera fase edificatoria en el cual se aprovechan las piedras cortadas sobrantes para sentar un muro no portante sobre un muro portante, esto con la finalidad de impedir el perjuicio que genera a las áreas de secano los fuertes vientos que corren de SW a NE la mayor parte del día. (Fig. 2).

El conjunto 2A se adosa al área de secano del conjunto 1A y está conformada por cinco recintos cuadrangulares (1, 2, 3, 4 y 5) alineados con la segunda fila de recintos del conjunto $1 \mathrm{~A}$, con un espacio estrecho en la sección posterior que serviría para el tránsito hacia los depósitos. Al lado NE del recinto 5 se observa un estrecho corredor de $1 \mathrm{~m}$ de ancho, de planta rectangular que termina en la sección anterior del conjunto en un espacio abierto en la fachada desde el que se divisa una hendidura en la deposición en la cual pudo estar una posible escalinata de acceso al sector A, también se observa asociado a este corredor una banqueta que sirve de desnivel hacia el espacio de transito dentro del edificio. Continuando hacia el noreste se observa un espacio rectangular delimitado por 


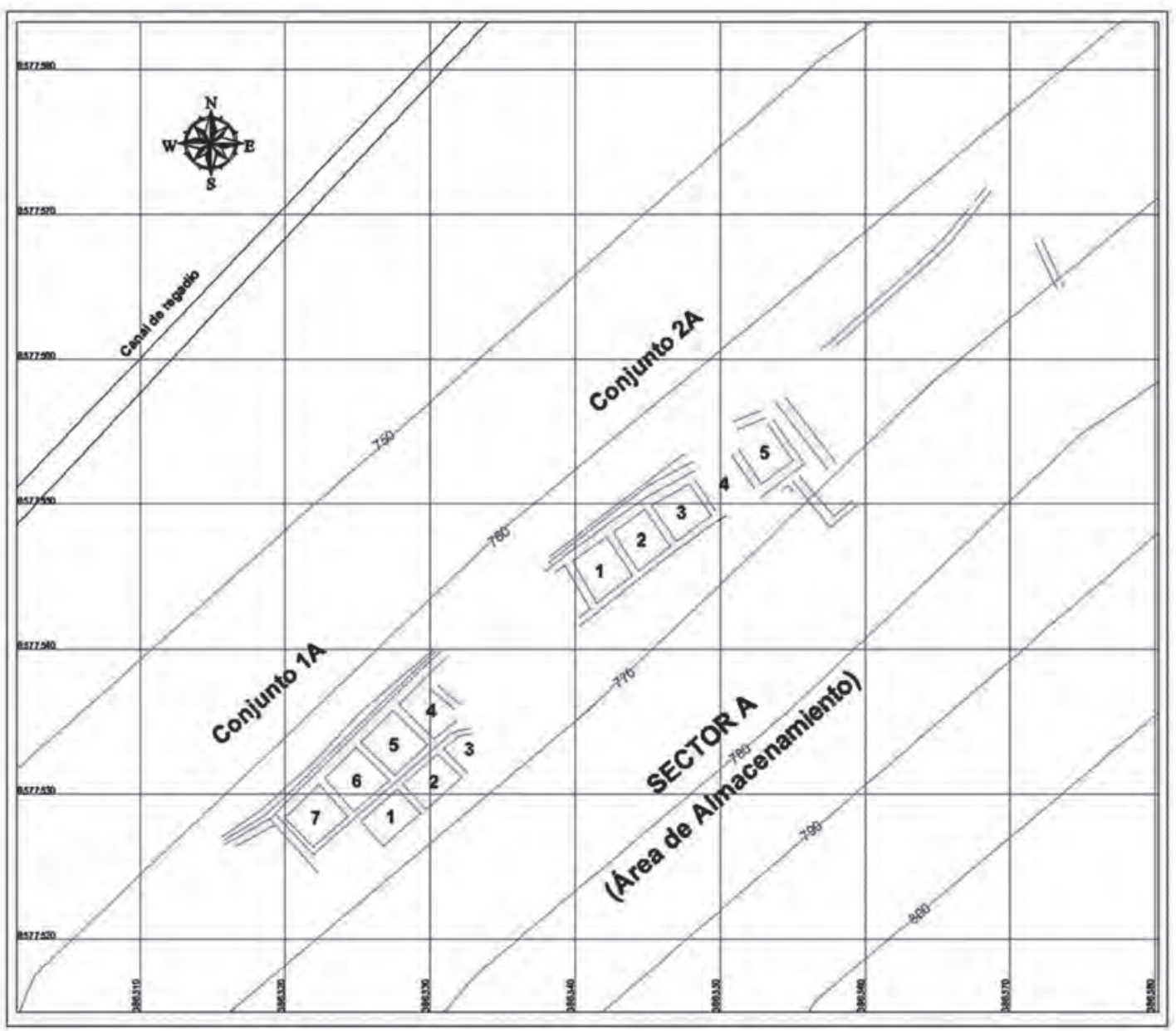

Figura 2. División del sector A.

la prolongación de la fachada en la sección anterior, por un muro del corredor en el lateral izquierdo (en el cual se observa un estrecho acceso), por el corte a la roca firme en la sección posterior y por un muro portante en el lado opuesto al muro del corredor. Este espacio también cumpliría las mismas funciones que el área de secano identificada en el conjunto $1 \mathrm{~A}$, pero en este caso asociados a los recintos de acopio del 2A. El muro portante que delimita el tendal en la sección NE (opuesto y paralelo al muro del corredor) presenta sobre su cabecera el adosamiento de otro pequeño muro, con piedras de menor tamaño y mayor argamasa en las uniones, de paramento irregular, identificada como muro no portante cumpliendo solo con la función de cortaviento más no de soporte de cargas horizontales o verticales. En este conjunto también se presenta la prolongación de los dos muros arriostrados que sirven de soporte a las fuerzas que se generan sobre las bases del muro de fachada debido al peso de las cargas al interior de los depósitos y a la vez por la fuerte inclinación de la pendiente.

El sector B se asienta sobre la ladera baja del cerro y se encuentra al lado suroeste en relación al primer sector. Sus recintos están orientados hacia el noroeste sobre una superficie moderadamente pronunciada en la cual fue necesaria la construcción de dos plataformas sobre la que se adosan recintos de planta rectangular y cuadrangular, en dos casos se observa que estos recintos tenían estrechos 
accesos en sus alzadas, en los demás no se logra definir debido al grado de deterioro de los muros que han colapsado o se encuentran cubiertos por los deslizamientos aluviónicos que se producen en un pequeño cono de deyección formado en el cerro; sin embargo es posible que también hayan contado con una fácil entrada a sus interiores. Los muros son de menor ancho y altura en comparación a los del sector A (debido a su funcionalidad de recintos habitacionales), asimismo su acabado es más sencillo con un revoque más ligero y un paramento más irregular. Este sector se ubica más cerca al área de cultivos y sobre su superficie se observan fragmentos de bordes de cerámica utilitaria, asas y fragmentos de cuerpos de recipientes con restos de hollín. Consideramos a este sector como el área doméstica del personal que se encargaba del mantenimiento de los depósitos, recepción y conteo de las cargas, así como también del procesamiento de los productos botánicos (secado); este personal posiblemente estuvo conformado por habitantes de la zona que rotaban en esta actividad a favor del Estado. En una de las plataformas se observa la inserción de un recinto ovalado de un solo paramento construido sobre el relleno de la plataforma, otro recinto de las mismas características aparece sobre el relleno constructivo de un muro de contención que servía para evitar los deslizamientos del talud en la sección superior del sector B, estos al parecer corresponden a recintos funerarios posteriores a la etapa de abandono, lo cual correspondería a una tercera fase constructiva, ya que su construcción es sobre la inserción de rellenos de plataformas destinadas a recintos para descanso, además estas estructuras rompen el orden del diseño en este sector. Esta misma inserción de posibles tumbas posteriores a la etapa de abandono también se observan en los sectores habitacionales de las colcas de Peña de la Cruz de San Juan y Huanaco en el valle medio de Cañete, conformando una característica funeraria repetitiva en nuestra zona de estudio.

\section{BREVE INTERPRETACIÓN DE LAS UNIDADES DE EXCAVACIÓN}

U. Exc: I (Recinto 7): Recinto que se construye en una fase posterior al recinto adjunto, lo cual se evidencia en el adosamiento de dos de los muros; presenta un piso de arcilla limosa con superficie lisa algo agrietada producto del desgaste erosivo y del uso. El mencionado piso muestra una ligera curvatura en el adosamiento con los muros, lo cual le permitía una mejor ventilación de los productos almacenados. Por el material arqueológico hallado se puede deducir que se trata de un recinto utilizado como depósito de especies botánicas, predominando el almacenamiento del fruto del maíz que al parecer se guardó con partes de la planta y con el fruto cubierto por su misma bráctea, por lo cual se observa poca fragmentería de cerámica que posiblemente corresponde a los otros productos menores que se alternaron en el almacén, como por ejemplo maní, ají y lúcuma, los cuales si necesitaron de vasijas para su acopio.

El recinto se edifica sobre una planicie previamente tratada, iniciando con la construcción de dos muros que se adosan a otros dos muros portantes existentes que pertenecen al recinto adjunto y al muro eje del conjunto arquitectónico, de esta manera se forma un espacio cuadrangular (U. Est. 6), en cuya base se realiza un piso conformado por arcilla fina (U. Est. 5), sobre el cual en el momento de abandono se forma una acumulación de arcilla limosa con piedras angulosas producto del colapso de pequeños espacios de las cabeceras de los muros y restos de camillas de tallos de maíz, así como también restos botánicos de las especies almacenadas en dicho depósito (U. Est. 4), luego de esto aparece un pequeño montículo en una esquina del recinto con material arqueológico removido del estrato anteriormente mencionado, al parecer se trata de una remoción durante eventos de saqueo del depósito ya en momentos de abandono del edificio (U. Est. 3).

Posteriormente se suceden diversos momentos de caídas de piedras angulosas, cascajo, grava y gravilla producto del desgaste de fragmentos de la roca firme, deslizamiento del talud rocoso del cerro y del colapso de pequeños espacios de las cabeceras de los muros (U. Est. 2). Al mismo tiempo y posteriormente sucede un evento continuo de arrastre eólico de tierra fina que cubre la cabecera de los muros y las piedras y grava que se depositaron en la planta del recinto (U. Est. 1). 
U. Exc: II (Recinto 1): Recinto que se adosa a la roca firme, se trata de la primera fila de recintos construidos en la zona luego de cortar parte de la roca firme y limpiar parte del talud. Este recinto posee un muro de contención con un relleno de barro que le da una mayor consistencia para la resistencia del peso que ejerce no solo la roca firme sino también la caída del talud de cascajo y piedras angulosas. Luego de construido el muro de contención se realizó el recinto cerrado por cuatro muros portantes de piedras angulosas con argamasa de arcilla de alta plasticidad, con un piso de arcilla limosa que presenta un buen acabado de superficie, con las esquinas muy curvas y todo el adosamiento a los muros con una ligera elevación lo cual le permitía una mejor ventilación de lo almacenado. En la sección superior tenía una cubierta de torta de barro sobre caña brava y posiblemente con vigas de tallo grueso. Dentro de la torta de barro se aprecian ramas de sauce y caña brava que le daban una mayor resistencia a la horizontalidad como un tipo de amarre del barro, lo cual a la vez permitía el transito sobre el techo que cubría gran parte del recinto dejando un espacio abierto para poder ingresar al interior de la colca las especies botánicas desde la zona que da al muro anterior. Los productos aquí almacenados fueron maíz, guayaba, lúcuma, algodón, maní, mate, pacay y frejol.

El recinto se inicia con la preparación del espacio, retirando el cascajo del talud y cortando la roca firme para el espacio necesario, luego se construye un muro de contención con un relleno de barro tratado para un mejor amarre y soporte a la roca firme (U. Est. 8). Prontamente se construye el recinto y su adjunto en la misma fila; este recinto está formado por 4 muros portantes que diseñan un espacio cuadrangular (U. Est. 7), en cuya base se realiza un piso de arcilla limosa con superficie alisada y con ciertas curvaturas en el adosamiento de los muros generando una mayor circulación del viento dentro del depósito, este piso (U. Est. 6) posiblemente presenta un relleno de arcilla fina. Sobre la superficie del piso se observa una deposición natural de arena y tierra de arrastre eólico, esta deposición se debe a la presión del contenido de las unidades estratigráficas superiores que dejan pasar el material más fino y delgado (U. Est. 5), sobre ella aparece una deposición de arcilla, piedras angulosas y cascajo con abundante material botánico, predominando los tallos de caña brava, sauce y carrizo que posiblemente corresponden a la estructura de la techumbre caída ya que se asocia a fragmentos de argamasa de la cubierta, también se observan abundantes restos de frutos de los productos almacenados (U. Est. 4). Sobre dicha deposición se observan segmentos de la cubierta hechos de arcilla limosa con gravilla que llevaban en su interior cañas bravas para un mejor amarre en la horizontalidad, estos terrones aparecen al lado de cascajo y grava (U. Est. 3); arriba de lo mencionado aparece una gran deposición de piedras angulosas grandes, medianas y pequeñas, así como también cascajo y grava producto del deslizamiento del talud que cubre parte de la roca firme en la sección superior del cerro (U. Est. 1), esta deposición cubrió la sección del techo que aparece sobre la cabecera del muro portante que se construye hacia el lado de la roca firme (U. Est. 2).

U.Exc: III (Recintos 3 y 4): Se excavó una trinchera que abarca dos recintos. Ambos han sido renovados en su diseño espacial. El primero al parecer no era un recinto y se trataba solo de un espacio lateral del conjunto 1A. Posteriormente dicho espacio fue transformado al desmontar parte del muro eje y anexándole a este un muro semicircular, de esta manera se forma el recinto de la sección posterior, el cual al parecer (por las diferentes alturas de las cabeceras de los muros) no poseía un techo fijo de barro. En el interior de este recinto semicircular se realizó un desnivel formado por un muro de contención y su respectivo relleno de barro, sobre el cual se halló dos artefactos de diatomitas que pudieron servir como pesticida natural no venenoso, ya que la ingesta de sus partículas de sílice causa lesión del tubo digestivo de los insectos y roedores, además la fijación de estas partículas sobre el cuerpo de los insectos les causa también lesiones que implican su muerte por deshidratación. Estos artefactos también han sido hallados durante las excavaciones llevadas a cabo por el Lic. Javier Alcalde (comunicación personal) en la provincia de Chincha, resultando también estar compuestas por diatomita. Tanto Javier Alcalde como el geólogo Hugo Rivera Mantilla (quien observó nuestros 
artefactos) nos señalan que la cantera más próxima a Cañete sería la ubicada en Pisco donde existen enormes estratos de diatomitas, por lo que es probable corresponda a esa zona desde el cual se realizó su tránsito hasta las colcas del valle medio de Cañete utilizando los caminos incas que unían diversas edificaciones estatales. (Fig. 3).

El otro recinto se encuentra en la segunda fila de depósitos y al parecer en un momento anterior tuvo una profundidad parecida a la del recinto adjunto en la misma fila, sin embargo posteriormente fue sellada en su sección inferior y se recortó con un pequeño muro portante sobre el cual luego se construyó un piso que conecta el área de secano con el área de depósitos.

En el tiempo de abandono dicho recinto fue saqueado y cortaron tanto el sello antrópico como las deposiciones naturales que se formaron en su sección superior.

Ambos recintos pertenecen a la última fase de construcción de la estructura, realizando cambios importantes en el diseño y

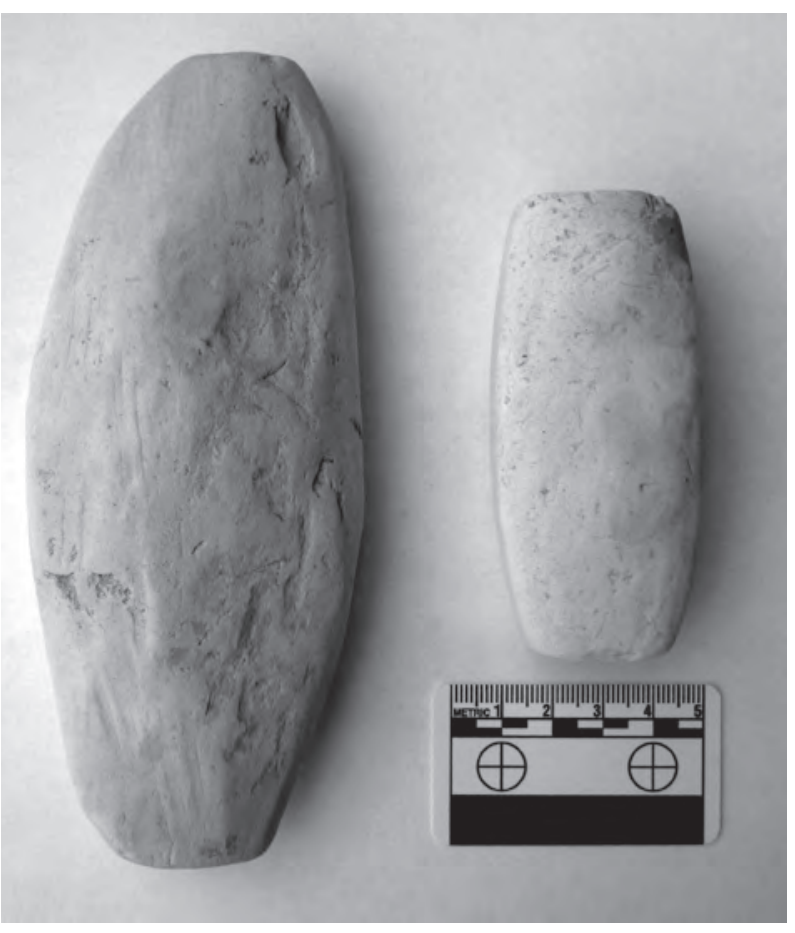

Figura 3. Artefactos de diatomitas. aprovechamiento de los espacios.

En cuanto a las relaciones estratigráficas se registró por recintos. El primer recinto es de planta rectangular (recinto 4) formado por 3 muros portantes que se adosan a un pequeño muro de pocas hiladas (U. Est. 12) sobre el cual se sobrepone el piso del área de secano (U. Est. 10). Este recinto cuadrangular en un momento fue de la misma altura que los adjuntos en la misma fila; sin embargo, luego sufrió cambios en el planeamiento del espacio, en ese momento se realiza un relleno de arcilla, piedras angulosas y cascajo (U. Est. 15), el cual en un momento posterior al abandono del sitio es saqueado y cortan la mencionada deposición formando un hoyo irregular (U. Est. 14) en el que se depositan escombros de lo removido en el saqueo (U. Est. 13).

El segundo recinto es de planta semicircular (recinto 3) formado por un muro portante que es el eje de toda la estructura y un muro divisorio de depósitos (U. Est. 5) junto a un muro semicircular no portante cierran el espacio del recinto (U. Est. 4). Este muro se adosa directamente a la roca firme (U. Est. 2). Al igual que el muro de contención de piedras angulosas pequeñas y medianas en la sección posterior del recinto (U. Est. 3). Dentro del mencionado recinto existe un desnivel formado por un pequeño muro de contención y relleno de barro en su sección posterior (U. Est. 8). La sección restante fue rellenada con arcilla fina y cascajo en un momento de abandono del recinto dándole estabilidad al muro no portante (U. Est. 9). Tanto sobre la unidad estratigráfica 8 como sobre la 9 se deposita una capa de pequeños terrones de arcilla con restos de caña brava pertenecientes a la cubierta del recinto adjunto y restos botánicos de lo almacenado (U. Est. 7) y sobre ella se deposita una capa de arcilla con restos de la cubierta del recinto adjunto, piedras angulosas de la caída de la cabecera del muro semicircular y cascajo (U. Est. 6).

Sobre las unidades estratigráficas del recinto rectangular y del recinto semicircular aparece la deposición de piedras angulosas, cascajo y grava (U. Est. 1) producto del deslizamiento del talud del cerro en la sección posterior al muro de contención. 
U.Exc: IV (Frontis del conjunto 1A): Espacio exterior a los recintos de almacenamiento, en el cual se observan dos muros de arriostre de menor altura que se adosan de forma paralela al muro de fachada permitiéndole una mayor estabilidad a la longitud de la fachada, estos se adosan a una plataforma que sirvió de camino compuesta por un muro de contención con relleno de cascajo y grava, el cual fue revestido con un piso de arcilla limosa que permitía la facilidad del tránsito sobre ella para llevar las cargas a lomo de camélidos hasta la fachada del conjunto de colcas, en esta zona la carga se pasaría al hombro de las personas para ser transportadas hacia el área de secano. Este espacio excavado presenta información arquitectónica importante ya que se observan las técnicas arquitectónicas de soporte de los muros largos de fachada en un talud con fuerte inclinación; asimismo se observa la evidencia del camino que posiblemente conducía a las otras colcas que aparecen en el valle medio de Cañete, el cual pudo seguir siendo utilizado en tiempos posteriores al abandono de la función del sitio arqueológico.

En cuanto a las relaciones estratigráficas es necesario mencionar que en la sección anterior a los recintos se realiza un camino que cruza de manera longitudinal por toda la fachada del conjunto arquitectónico del sector A. Este camino está conformado por un relleno de cascajo, grava y gravilla que tuvo un muro de contención en su sección anterior (U. Est. 8); sobre este relleno se elabora un piso de barro de poco tratamiento para la facilidad del tránsito (U. Est. 6). Dicho camino está adjunto a la base del segundo muro arriostrado que se adosa al muro de fachada, este muro arriostrado (U. Est. 7) permite mayor estabilidad a la estructura. Sobre la cabecera de este muro aparece una concentración de arena producto de la acumulación de agua de lluvias (U. Est. 5), sobre la cual se observó coprolitos de ganado vacuno (U. Est. 4) que posiblemente corresponde al re-uso del camino en épocas posteriores al abandono del conjunto arquitectónico en el cual ya se había insertado la crianza de vacas en la zona. Dichos animales posiblemente eran trasladados por este camino prehispánico para evitar el daño en las áreas de cultivo de la zona baja aledaña al cerro. Dicho camino probablemente fue limpiado en diversos momentos de su re-uso, por lo cual se retiró el excremento del ganado de la superficie del piso desgastado arrojando algunas de estas sobre la cabecera de los muros arriostrados del conjunto arquitectónico en desuso. Sobre todo este espacio que conforma la unidad de excavación IV se observan fragmentos de argamasa de una cubierta (U. Est. 3), así como también restos de tallos de caña brava, sauce y carrizo junto a fracciones de frutos botánicos (U. Est. 2) que posiblemente corresponden a la cubierta y a lo almacenado en el recinto posterior a la excavación, que llegó hasta este espacio debido al arrojo de dicho material en un momento de saqueo del recinto 7. Sobre esto se observa una deposición de cascajo, grava y gravilla con tierra fina de arrastre eólico (U. Est. 1).

\section{ANÁLISIS ARQUITECTÓNICO DE LAS UNIDADES DE EXCAVACIÓN}

Recinto 7.- Recinto cuadrangular compuesto por cuatro muros portantes adosados entre sí, estos muros son gruesos y están elaborados para soportar no solo su propio peso, sino también el de la cubierta y el del tránsito sobre sus cabeceras, por esta razón el remate en hileras de piedras asentadas de manera horizontal toma la función de reducir el desgaste de las cabeceras durante el tránsito para el llenado o vaciado de las colcas. El muro posterior del recinto 7 se adosa a un muro paralelo cuya prolongación viene a ser el muro anterior del recinto 1. Estos dos muros se adosan uno al otro en el centro de la estructura 1A formando el eje principal del conjunto arquitectónico, su función es la de soportar los pesos que pueda generar las cargas al interior de los recintos, por lo cual el adosamiento de dos muros paralelos evitaría el pandeamiento producido por la fuerza interna de los recintos.

Se observa cierto desplazamiento en el muro de fachada, lo cual permitió observar que este recinto se adosaba a las edificaciones existentes de una primera fase constructiva; por tal motivo, hemos identificado este hecho como una segunda fase, en la cual aumentan la cantidad de recintos debido a una mayor necesidad de acopio en la zona, lo cual posiblemente corresponda a una mayor cantidad de personal estatal en los centros administrativos, ceremoniales o militares del valle medio de Cañete. 
El muro de cortaviento que aparece sobre un muro portante en el lateral de este recinto posiblemente corresponda a un segundo momento constructivo dentro de esta segunda fase, en la cual se construye el muro lateral portante con la finalidad de servir de soporte al muro lateral del recinto $7 \mathrm{y}$ a la vez para servir de base al muro cortaviento que no podía ser alzado sobre el muro del recinto ya que este presentaba una cubierta fija.

La elaboración de cierta curvatura, tanto en el revoque de las esquinas de unión de los paramentos internos así como también en el adosamiento del piso con el muro, permitió una mayor ventaja de ventilación de los productos botánicos almacenados y a la vez facilitaría la limpieza del recinto durante el mantenimiento común luego de retirado los productos.

Recinto 1.- Recinto cuadrangular compuesto por cuatro muros portantes adosados entre sí, los cuales presentan el mismo adosamiento con cierta curvatura en el interior tanto entre muros como con la unión del piso, tal como se describió para el recinto 7. Este recinto se ubica en la primera fila de depósitos y al parecer corresponde al primer momento constructivo de la primera fase, en el que se corta la roca firme para ganar espacio sobre una superficie de pendiente pronunciada, la cual tuvo que ser rellenada para lograr una superficie plana.

En el muro posterior del recinto se observa un nicho trapezoidal en la sección superior central que posiblemente sirvió para guardar una conopa o algún quipu para el conteo de lo almacenado. La aparición de este nicho nos confirma que los depósitos no eran llenados hasta la parte superior, sino más bien hasta un poco más de la mitad, dejando el resto de espacio para una buena ventilación del interior del recinto. La forma trapezoidal de este nicho nos confirma que desde el primer momento de la primera fase constructiva la obra es de data Inka, ya que esta forma es característica de las edificaciones incaicas.

Se observa como medio preventivo la construcción de un muro de contención en la sección posterior al recinto, esto serviría para soportar la carga de los deslizamientos del talud del cerro, el mismo que tuvo que ser limpiado cada cierto tiempo con la finalidad de evitar cargas innecesarias sobre el muro de contención, lo cual podría ocasionar pandeamiento o el colapso del mismo.

La elaboración de un techo de barro con ramas de sauce, tallos y hojas de caña brava (con escasa presencia de carrizo) y vigas de molle mostraría el aprovechamiento de los recursos botánicos que tenían a la mano en beneficio de la construcción de edificios. Estas especies se presentan de manera silvestre en la zona del valle medio y es innecesario un monitoreo de su crecimiento, por lo cual el único trabajo necesario fue cortarlos de las acequias o márgenes del río y el respectivo transporte hasta la zona donde se edificaron las colcas; es decir, hasta la ladera media del cerro.

Recinto 3.- Recinto semicircular compuesto por tres muros portantes y un muro no portante que solo recibe el peso de su propia alzada. Este recinto se ubica en la primera fila de depósitos; sin embargo corresponde a una segunda fase constructiva, en el que se presume la necesidad de aumentar los espacios de almacenamiento. Para la construcción de este nuevo recinto se corta el muro eje del conjunto arquitectónico y se le adosa un muro no portante de forma semicircular que termina en un corte en la roca firme y cierra el espacio con la prolongación del muro de contención que se asienta sobre el muro portante que en la fase anterior era el muro lateral derecho del conjunto $1 \mathrm{~A}$, el cual se convierte en un muro divisorio de colcas. En el interior de este recinto se observan dos desniveles compuestos por un pequeño muro de contención a la mitad del espacio, formando el primer nivel a escasos metros de la cabecera de los otros muros. Por lo anteriormente mencionado y por la diferencia de altura entre las cabeceras de los muros podemos deducir que dicho recinto no presentaba una cubierta fija tal como se evidencia para los otros dos recintos excavados. (Fig. 4). 


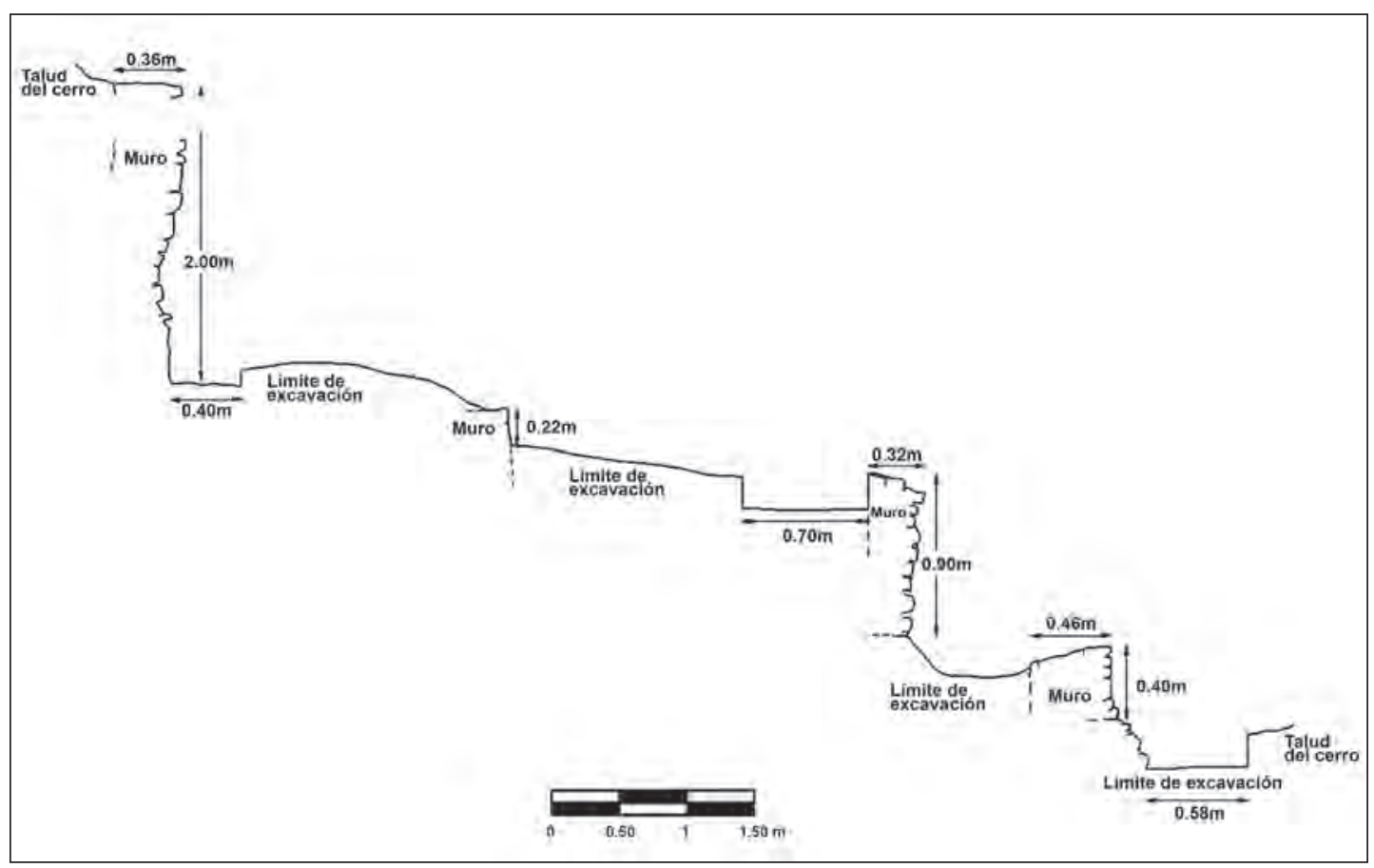

Figura 4. Corte perfil de la unidad de excavación III.

Camino en el frontis del conjunto arquitectónico 1A.- Sección de camino formado por un estrecho espacio con una superficie de arcilla y grava que cubre parte del segundo muro arriostrado que se adosa a la fachada del conjunto arquitectónico. Para la realización de este camino sobre una pendiente pronunciada fue necesaria la construcción de un muro de contención de piedras angulosas pequeñas y aparejo irregular, el cual fue relleno de cascajo, grava y gravilla para formar la base del camino. Este camino pasaba por todo el frontis del sector A y se prolongaba por la ladera media del cerro. Parte de este camino hemos logrado observar durante nuestras prospecciones en las colcas de Peña de la Cruz de San Juan, Uchupampa y Huanaco, ubicados también en la ladera media del cerro, en el mismo margen del valle medio; por lo cual cabe suponer que este camino servía de conexión entre las mencionadas colcas. (Fig. 5).

\section{ANÁLISIS BOTÁNICO DE LAS UNIDADES DE EXCAVACIÓN}

El análisis botánico de los restos hallados en las cuatro unidades de excavación mostró la identificación de las siguientes especies:

1. Unidad de Excavación I (Recinto 7):

- Tusas de maíz, brácteas de maíz, tallos de maíz, legumbre de maní, ramas terminales de sauce, semillas de frejol negro, semillas de pallar de los gentiles, semillas de ají, epicarpio de ají, legumbre de pallar, epicarpio de lúcuma, semilla de algodón, fibra de algodón de color marrón y beige, tallos de caña brava. (Fig. 6).

2. Unidad de Excavación II (Recinto 1):

- Tallos de algodón, tallos de caña brava, tallos con hojas de caña brava, hojas de caña brava, tusas de maíz, semillas de maíz, brácteas de maíz, semillas de frejol negro, baya de guayaba con semillas y mesocarpo, legumbre de pacay, ramas terminales de sauce, ramas terminales de molle, tallos de molle, soguillas de junco, epicarpio de mate. 


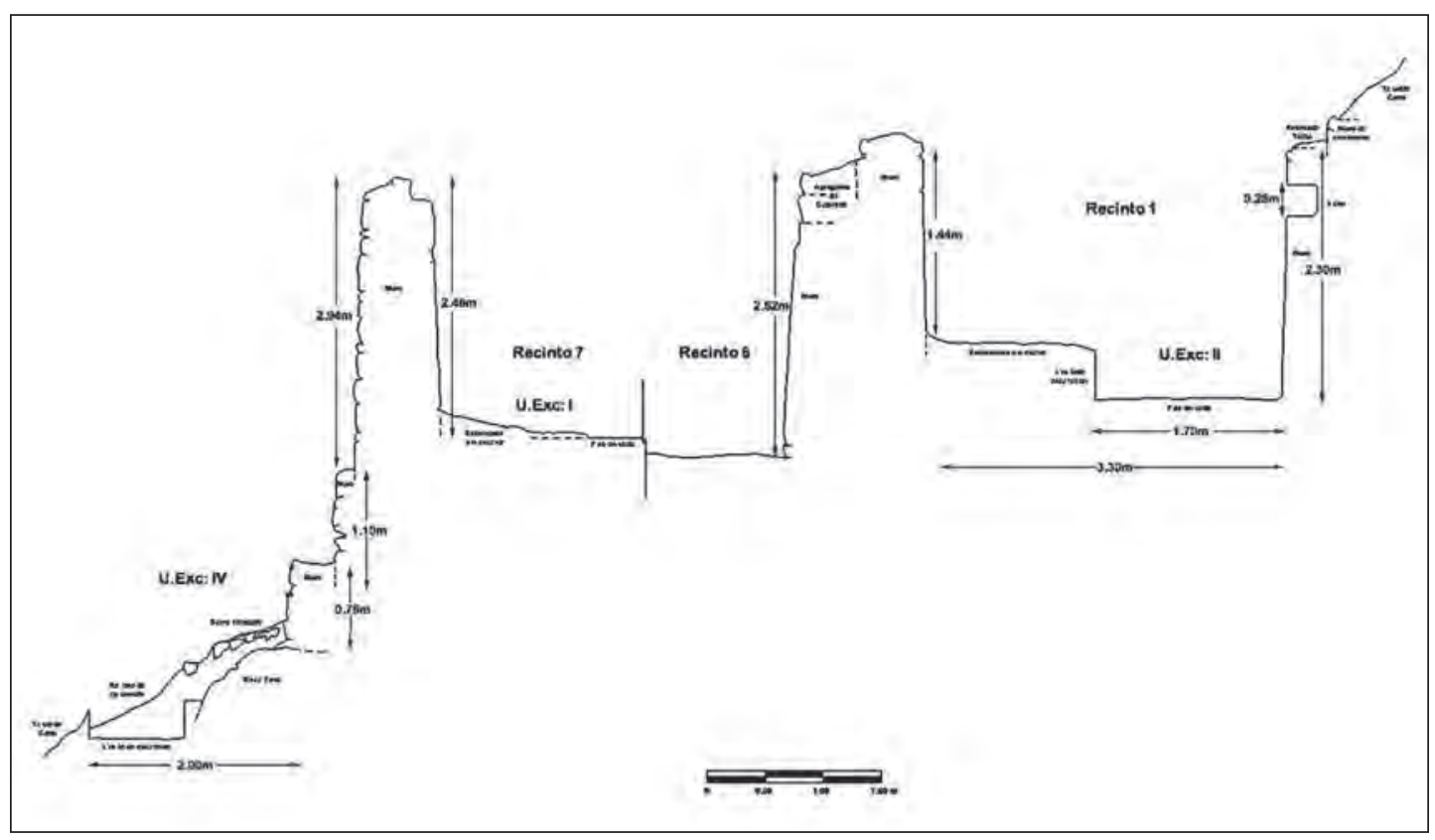

Figura 5. Corte transversal de las unidades de excavación I, II y IV

3. Unidad de Excavación III (Recinto 3):

- Tusas de maíz, semillas de lúcuma, semillas de pallar de los gentiles, epicarpio de mate, tallos de cola de caballo, legumbre de frejol, legumbre de maní, hojas de sauce, semillas de calabaza, tallos de caña brava, epidermis de ají, pedúnculos de ají, semillas de algodón, semillas de coca, brácteas de algodón. (Fig. 7).

4. Unidad de Excavación III (Recinto 4):

- Tusas de maíz, tallos de maíz, brácteas de maíz, tallos de caña brava, hojas de caña brava, legumbre de maní, semilla de lúcuma, tallos de achira, semillas de coca.

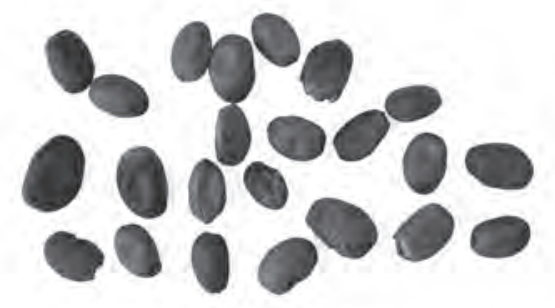

$$
0
$$

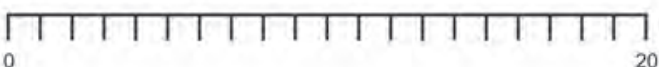

Figura 6. Semillas de pallar de los gentiles.
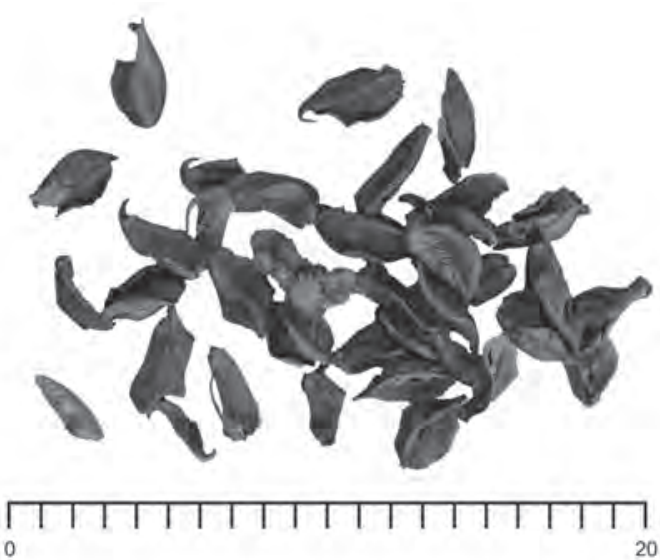

Figura 7. Brácteas de algodón. 
5. Unidad de Excavación IV (Frontis del conjunto 1A):

- Tusas de maíz, brácteas de maíz, legumbre de pacay, legumbre de maní, fruto de maní, legumbre frejol, semilla de frejol, legumbre de pallar de los gentiles, fibra de algodón, fruto de guayaba, hoja de caña brava, mesocarpo de lúcuma, pedúnculo de ají, tallo y raíz de caña brava, tallos de caña brava, hojas de caña brava, tallos de sauce, hojas de sauce, tallos de carrizo, hojas de carrizo.

Luego de mencionar las especies botánicas identificadas en cada una de las unidades de excavación el siguiente cuadro nos explica la posibilidad de que dichas especies hayan sido propias de la zona del valle medio de Cañete, y no correspondan a especies transportadas desde otras zonas. Cabe destacar que el distrito de Pacarán tiene sus terrenos de cultivo entre los 600 y 900 msnm. (Cuadro 1).

En nuestra muestra se observa que los frutos del maíz se almacenaron con las brácteas puestas, de esta manera se evita el aplastamiento del fruto. Al hallarse estos frutos con partes de tallos y hojas se deduce que su cosecha corresponde a zonas cercanas a la edificación, ya que de otra manera hu-

Cuadro 1. Especies botánicas halladas y su respectivo biotopo.

\begin{tabular}{|l|l|l|}
\hline Nombre común & \multicolumn{1}{|c|}{ Biotopo } & \multicolumn{1}{|c|}{ Altitud } \\
\hline Maní & Áreas de cultivo & $0-600 \mathrm{msnm}$ \\
\hline Chilca & Bosque ribereño & $0-1200 \mathrm{msnm}$ \\
\hline Pallar de los gentiles & Áreas de cultivo & $200-1800 \mathrm{msnm}$ \\
\hline Achira & Áreas de cultivo & $250-4000 \mathrm{msnm}$ \\
\hline Ají & $\begin{array}{l}\text { Bosques secundarios muy húmedos montanos, cam- } \\
\text { pos de cultivo, terrenos arcilloso arenosos y terrenos } \\
\text { arcillosos }\end{array}$ & $0-2000 \mathrm{msnm}$ \\
\hline Calabaza & Suelos húmedos. Campos de cultivo. & $0-2000 \mathrm{msnm}$ \\
\hline Zapallo & Suelos húmedos. Campos de cultivo. & $0-1500 \mathrm{msnm}$ \\
\hline Cola de caballo & Zonas húmedas, acequias. & $0-1200 \mathrm{msnm}$ \\
\hline coca & Áreas de cultivo & $500-1800 \mathrm{msnm}$ \\
\hline Algodón & $\begin{array}{l}\text { Campos de cultivo. Laderas, terrenos llanos, arenoso- } \\
\text { húmedos, al borde acequias, totorales. }\end{array}$ & $100-1600 \mathrm{msnm}$ \\
\hline caña brava & $\begin{array}{l}\text { Suelos húmedos, marginal de ríos, riachuelos o ace- } \\
\text { quias }\end{array}$ & $0-1500 \mathrm{msnm}$ \\
\hline Mate & $\begin{array}{l}\text { Suelos húmedos. Campos de cultivo. } \\
\text { Frejol }\end{array}$ Áreas de cultivo & $0-2000 \mathrm{msnm}$ \\
\hline Carrizo & $\begin{array}{l}\text { Suelos húmedos, marginal de ríos, riachuelos o ace- } \\
\text { quias }\end{array}$ & $0-2900 \mathrm{msnm}$ \\
\hline Lúcuma & $\begin{array}{l}\text { Suelos arenosos. Marginal de caminos, acequias y } \\
\text { campos de cultivo. }\end{array}$ & $0-3000 \mathrm{msnm}$ \\
\hline Guayaba & $\begin{array}{l}\text { Suelos arenosos. Marginal de caminos, acequias y } \\
\text { campos de cultivo. }\end{array}$ & $0-2000 \mathrm{msnm}$ \\
\hline Sauce & $\begin{array}{l}\text { Suelos arenosos. Marginal de caminos, acequias y } \\
\text { campos de cultivo. }\end{array}$ & $0-2000 \mathrm{msnm}$ \\
\hline Boliche & $\begin{array}{l}\text { Suelos arenosos. Marginal de caminos, acequias y y } \\
\text { campos de cultivo. }\end{array}$ & $0-2000 \mathrm{msnm}$ \\
\hline Pájaro bobo & Bosque ribereño & $0-1500 \mathrm{msnm}$ \\
\hline Maíz & $\begin{array}{l}\text { Campos de cultivo (suelos húmedos o medianamente } \\
\text { húmedos). }\end{array}$ & $0-3600 \mathrm{msnm}$ \\
\hline
\end{tabular}


biese significado una mayor fuerza de trabajo resuelta con el transporte desgranado del maíz como se observa en los almacenamientos de Huanuco Pampa y Huamachuco. De esta manera el maíz pudo ser almacenado directamente sobre el piso del recinto sin necesidad del uso de costales o vasijas, ya que los mismos tallos y hojas le sirvieron de almohadilla.

En los recintos excavados se observa la presencia recurrente de maíz y frejol, esta asociación posiblemente corresponde a una práctica agrícola sostenida, donde debido al desgaste del suelo por parte de ciertos cultivos (como por ejemplo el maíz) se siembra de forma paralela o alterna diversos tipos de frejoles (Phaseolus vulgaris, Canavalia cf. plagiosperma, Phaseolus lunatus), los cuales inyectan nitrógeno al suelo y favorecen la reducción de malezas, siendo ello una buena explicación de la presencia y distribución de ambas especies en la muestra analizada.

Los tallos y hojas de caña brava, así como también los tallos de sauce corresponden a la composición de amarre de la argamasa que conformaba la cubierta. Sobre la cabecera del muro posterior que forma el recinto 1 se observó parte de la cubierta de barro con la conformación de ramas terminales de sauce que incluso aún conservaban sus hojas aserradas las cuales estaban asociadas a tallos de caña brava. También en la deposición arqueológica al interior del recinto se observó fragmentos de la argamasa de la cubierta, las cuales tienen insertas hojas o pequeñas partes de tallos de caña brava, con lo cual se verificó que esta especie era utilizada para la formación de los techos de barro. Los tallos de carrizo cumplirían la misma función que la caña brava, estas especies crecen juntas en las áreas húmedas, por tal motivo se cortaban en el mismo momento sin necesidad de selección ya que cumplen la misma función. Los tallos maderables, como por ejemplo el que posiblemente corresponde a molle, fueron utilizados como vigas de soporte de la cubierta, ya que son resistentes a pesos y además se hallaron en forma paralela entre ellos.

En nuestra muestra se observa la presencia mayoritaria de especies comestibles, lo cual se concatena con el hecho de que la mayor parte de las especies identificadas son cultivadas; es decir, la mayor parte de la producción agrícola corresponde a productos alimenticios. En base a la información referida a los usos alimenticios se construyó la siguiente pirámide nutricional, mostrando que la diversidad registrada completa sin problemas los requerimientos nutricionales de una persona; sin embargo, dicho dato solo debe ser complementado con los proporcionados por el contexto, además de contrastarse con las proporciones entre cada especie, aunque de todas maneras queda patente el hecho de que existió el potencial de generar alimento suficiente para el sustento de una población. (Fig. 8).

\section{CONSIDERACIONES FINALES}

1. La estrategia de construir depósitos en ambientes alejados de las poblaciones, en terrenos no propicios para la agricultura y en las laderas de los cerros sobre una superficie visible con impacto directo de los rayos solares y viento razonable es un patrón de diseño que fue repetido en muchos lugares donde llegó el Estado Inka, no solo en las cabezas de provincia sino también en centros administrativos menores que almacenaron bienes de consumo en favor del desarrollo de las actividades estatales. De esta manera el sitio arqueológico Pacarán 01 cumpliría con dicha función de recepción de los productos durante la cosecha de las áreas de cultivo cercanas o de influencia directa. Por tal motivo la edificación de Pacarán 01 cumpliría con la denominación de «estación de acopio» o «punto de acopio» y estaría relacionado con el tributo de la población local en beneficio del gobierno incaico. (Fig. 9).

2. El funcionamiento de estas colcas son el producto de un largo desarrollo tecnológico en el cual cabe destacar la ubicación en las laderas de los cerros fuera de las áreas de cultivo, evitando de esta manera la presencia de insectos y roedores, apoyado en una mayor ventilación de los productos almacenados, y en una exposición directa al sol lo cual ayuda a evitar la humedad en los recintos. A esto se suma las técnicas de construcción en el cual se observan que tanto entre los 


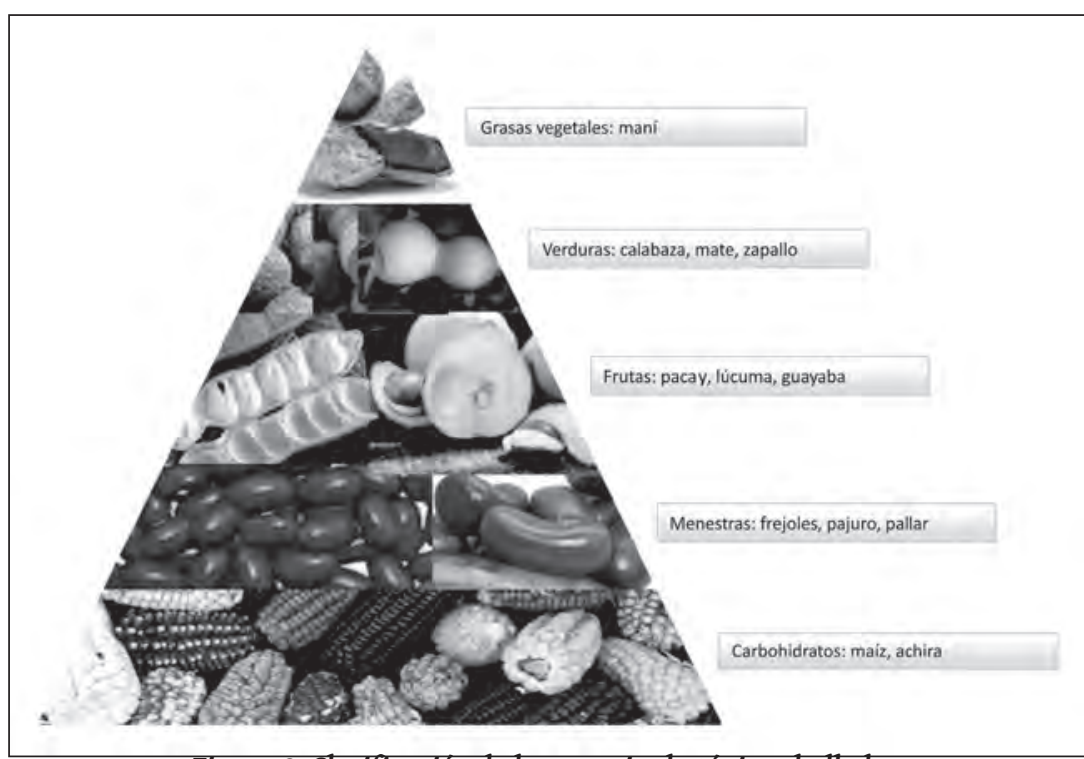

Figura 8. Clasificación de las especies botánicas halladas.

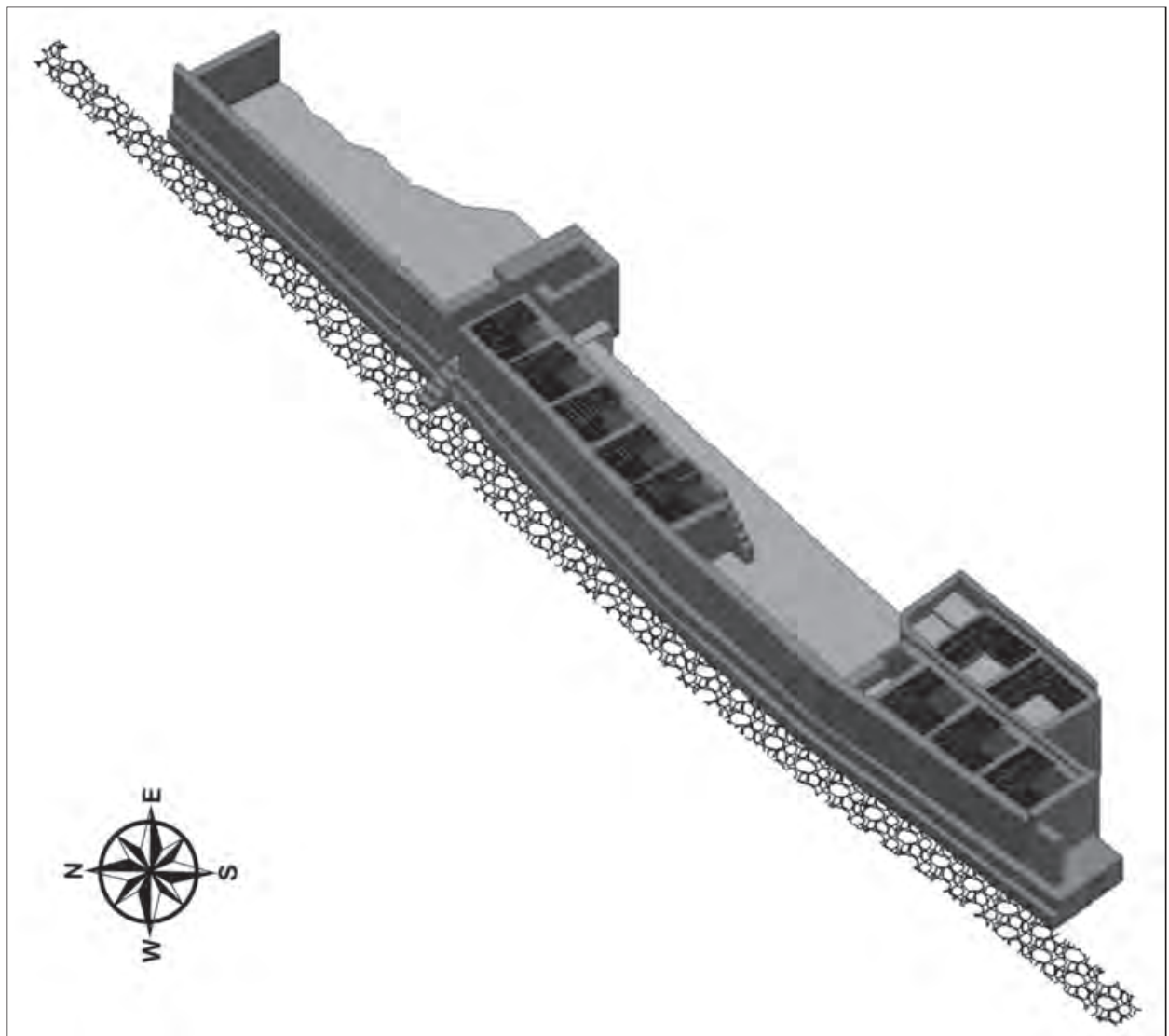

Figura 9. Reconstrucción hipotética del sector A. 
muros como en el adosamiento del piso existe cierta curvatura lo cual sirve para una mejor circulación del viento dentro de los recintos y para evitar la acumulación de desechos en las esquinas. También cabe destacar la agudeza para repeler la presencia de insectos que afecten los frutos almacenados, como por ejemplo mediante ramas de molle que fue fácil de conseguir en el valle medio y también por medio de artefactos de diatomitas, transportadas de otras zonas, que no solo repele a los insectos sino que además ayuda a mantener un ambiente libre de humedad.

3. El estudio botánico ha identificado que todas las especies almacenadas en los recintos excavados (maíz, maní, lúcuma, frejol, pallar, pallar de los gentiles, algodón, guayaba, coca, ají, achira, zapallo, mate, calabaza, pacay) fueron posibles de ser cultivadas en el valle medio, ya que se desarrollan en alturas dentro de las concebidas para este valle medio y en suelos característicos a los de la zona de estudio, además de contar también con el clima cálido y seco durante casi todo el año. De la misma manera el estudio botánico ha identificado que las especies utilizadas en la construcción de los recintos son propias del valle medio (sauce, molle, caña brava, carrizo, pájaro bobo) en su mayoría estas crecen en los bordes del río o en las márgenes de las acequias; es decir, se aprovechó los recursos de la zona para adoptarlas en la construcción de edificaciones que seguían un patrón diseñado en otro lugar por los arquitectos estatales.

4. Las colcas de Pacarán 01 es la primera edificación de este tipo de estructuras destinadas al acopio. Estas construcciones se extienden hasta el sitio arqueológico de Incawasi, por lo que pensamos haya servido para el mantenimiento del ejército, de la élite estatal y para las actividades ejercidas en dicho complejo arquitectónico. De esta manera el estado tomaría los complejos de colcas como la forma de apropiación de la producción social de los pobladores del valle medio de Cañete sujetos al incanato. Cabe mencionar que todos los productos hallados en las colcas excavadas son propias de cosechar en dicho espacio geográfico, mas existe en Pacarán 01 una ausencia de productos procedente de la zona alta (chuño, papa, quinua, quiwicha, oca, etc) que pudieron complementar la alimentación, a pesar de hallarse ligado a un camino Inca.

5. La excavación arqueológica en Pacarán 01 demostró que dichos recintos no presentan reutilización luego de las actividades estatales del incanato, esto se afirma al observar la ausencia dentro de los recintos de restos de coprolitos de ganados vacunos, caprinos u otros de la actividad ganadera realizada durante la etapa colonial, tal como si se observó en las colcas de Huanaco cercanas a Pacarán 01 que hasta hace pocos años se continuaban utilizando algunos recintos como corrales modernos. Tampoco se observa la presencia de basura doméstica ni otro tipo de evidencia de una posterior actividad de reutilización en el sitio, por lo menos esto aseveramos para el sector de colcas, más no para el sector B de recintos habitacionales, el cual no fue intervenido en esta temporada de investigación. Otro indicio que sustenta nuestra afirmación es la ausencia de frutos no oriundos de la zona andina en nuestra muestra recuperada, ya que bien se conoce en el valle medio luego de la llegada de los españoles se aclimataron una diversidad de productos aprovechando los suelos fértiles de la zona, entre ellos podemos mencionar al níspero, manzana, uva, dátiles y tuna. Tampoco se observan fragmentos de cerámica con alguna decoración de data colonial.

6. Si bien podemos afirmar que los recintos no fueron reutilizados, no sucede los mismo para el caso del camino que cruza por la sección anterior a la fachada del sector A del sitio arqueológico; la intervención de la unidad de excavación IV mostró evidencias de coprolitos de ganado vacuno sobre las cabeceras del segundo muro arriostrado al muro de fachada, lo cual puede referir que dicho camino era utilizado en épocas posteriores a la llegada de los españoles, ya que este camino permite un tránsito alejado de los terrenos de cultivo, por lo cual sería muy provechoso para la movilización del ganado vacuno sin dañar los campos de cultivo. Para que dichos coprolitos hayan llegado a la cabecera del muro arriostrado de poca altura cabe pensar en la posibilidad de un mantenimiento del camino, en la cual se limpia la superficie del camino arrojando los desechos 
hacia los lados, entre estos lados se cuenta la cabecera del muro mencionado. Por otro lado las entrevistas a los pobladores adultos mayores de la zona señalan haber observado hasta hace 50 años atrás parte de un camino que colapsó luego de la construcción de un estrecho canal de regadío en la falda del cerro, momento en el cual se produce un gran deslizamiento del talud del cerro cubriendo dicho camino colapsado y parte de pequeñas terrazas en la sección baja de la ladera del cerro.

7. La edificación de Pacarán 01 y otras colcas más ubicadas en el valle medio de Cañete muestran el aporte de un factor importante en la logística necesaria para realizar las actividades estatales contribuyendo con el suministro de productos alimenticios acopiados por los pobladores de la zona en favor de los trabajadores que realizaban actividades especializadas para el estado tal como son los administradores, sacerdotes y el ejército. Esto solo se lograría por medio de un control del estado hacia las fuerzas de trabajo de dicha sociedad como parte del tributo, posiblemente en grupos rotativos.

\section{Agradecimientos}

Este trabajo de investigación no hubiera sido posible sin la motivación de Guido Casaverde Ríos, con quien comparto el interés del estudio de temas incaicos, y quien a la vez se convirtió en el co-director del proyecto de investigación. A mis amigos Byllyban Oscco, Pedro Lira, Pedro Anicama y Gloria Esquivel, quienes generosamente me ayudaron en la etapa de campo y poco a poco se interesaron más en el valle de Cañete, realizando luego sus propios estudios arqueológicos en el tema relacionado. También es necesario manifestar mi gratitud a Yesenia Quispe y Cesar Padilla por el apoyo desinteresado en la etapa de gabinete; asimismo a Enrique Bellido por la colaboración en el análisis botánico.

También quiero dedicar este artículo a mi tío Manuel Espichan, quien en vida fuera un gran agricultor de la provincia de Cañete y de quien aprendí muchas cosas relacionadas a la botánica. 


\section{BiBLIOGRAFÍA}

ÁNGELES, Rommel

2010 «Algunos aspectos de la ocupación inca en la costa central: de Paramonga a Cañete». Inka Llaqta. Vol. 1: 143-171. Lima.

ÁNGELES, Rommel y Denise POZZI-ESCOT

2000 «Excavaciones en Huaca Malena, Valle de Asia». Arqueológicas. № 24: 63-75. Lima: Museo Nacional de Arqueología, Antropología e Historia del Perú.

2004 «Del Horizonte Medio al Horizonte Tardío en la costa sur central: el caso del valle de Asia». Boletín IFEA. № 33: 861-886.

BACA, Emily

2004 «Excavaciones en el Sitio de Uquira, Valle de Asia». Boletín de Arqueología. PUCP. № 8: 409-428.

BONAVIA, Duccio

1959 «Cerámica de Puerto Viejo-Chilca». Época Prehispánica. Vol. I: 137-168. Lima: Centro de Estudios Militares del Perú.

1982 Los Gavilanes. Mar, desierto y oasis en la historia del hombre.

BUENO, Alberto

1982 «Cañete Arqueológico: Un Futuro Promisor». Espacio: 64-69. Lima.

2007 «Introducción a la arqueología del distrito de Lunahuaná, valle de Cañete». Bitácora de Cañete. Año 1, № 2: 5-18.

CAMPOS, Carlos

2007 «Acerca de los Guarco. Breves apuntes de una sociedad prehispánica de la costa sur-central del Perú». Bitácora de Cañete. Año 1, № 1: 3-10.

2007 «Acerca de los Guarco, sus tierras, sus edificios y su entorno: una sociedad autónoma en la costa sur central peruana.» Tukuy Rikuq. Año 4, № 4: 43-50.

2007 «Villcahuasi o Los Huacones: la otrora capital de la sociedad Guarco en peligro de desaparecer». Tukuy Rikuq. Año 4, № 4: 60-62.

CANZIANI, José

2009 Ciudad y Territorio en los Andes. Contribuciones a la Historia del Urbanismo Prehispánico. Lima: PUCP.

CASAVERDE, Guido y Segisfredo LOPEZ

2010 «Principios Metodológicos para la Identificación y Registro Arqueológico de los Caminos Inka». Inka Llaqta. Año 1, Vol. 1: 79-101.

2011 El camino entre Inkawasi de Lunahuaná y la Quebrada de Topará: vía para la conquista Inca del señorío de Guarco. Lima: Ministerio de Cultura.

CHACALTANA CORTEZ, Sofía

2010 «Evidencias Arqueológicas en Camata Tambo, Tambo Inca ubicado en el Valle Alto de Moquegua, Andes Sur-centrales». Arqueología y Sociedad N²1: 145-170.

ECHEVARRÍA, Gori y Enrique RUIZ

2007 «Datos sobre la ocupación Inca en el valle medio de Cañete» Bitácora de Cañete; Año 1, №2: 49-56.

ENGEL, Frederick

1966 Geografía humana prehistórica y agricultura precolombina de la quebrada de Chilca I. Lima: Universidad Nacional Agraria La Molina.

GROBMAN, Alexander

1961 Races of Maize in Peru, Their Origins, Evolution and Classification. National Academy of Sciences National Research Council. Washington, D.C.

GROBMAN, Alexander \& Duccio BONAVIA

1978 Preceramic Maize on the North Central Coast of Peru. Nature, Hampshire. 
HARTH-TERRÉ, Emilio

1923 «La Fortaleza de Chuquimncu». Revista de Arqueología. № 1. Lima: 44-51.

1933 «Incahuasi. Ruinas Inkaicas del Valle de Lunahuaná» Revista del Museo Nacional. Tomo II. № 2: 101125. Lima.

1964 «El Pueblo de Huánuco Viejo». El Arquitecto Peruano: 320-321. Lima.

HUAYCOCHEA, Flor de María

1994 Qolqas, Bancos de Reserva Andinos, Almacenes Inkas, Arqueología de Qolcas. Cusco: Universidad Nacional de San Antonio Abad del Cusco.

HYSLOP, John

1984 «The Inka Road System». Studies in Archaeology New York: Academic Press: 85-99.

1985 Inkawasi. The New Cuzco. B.A.R. International Series 234. New York: Institute of Andean Research.

KENDALL, Ann

1976 «Descripción e Inventario de las formas arquitectónicas Incas. Patrones de distribución e inferencias arqueológicas». Revista del Museo Nacional. Tomo XLII: 13-96.

KROEBER, Alfred

1937 Archaeological explorations in Peru. Part. IV, Cañete Valley. First Marshall Field Archaeologycal Expedition to Peru. Anthropology Memoirs. Vol: II. № 4. Chicago: Field Museum of Natural History.

KROEBER, Alfred \& William STRONG

1924 The Uhle Pottery Collection from Chincha. University of California Publications in American Archaeology and Ethnology. Vol: XXI. № 3; pp: 1-54. Berkeley.

LARRABURE Y UNANUE, Eugenio

1941 [1893] Manuscritos y Publicaciones. Tomo II. Valle de Cañete. Historia y Arqueología. Lima.

MARCUS, Joyce

1985 Informe Anual de las excavaciones en Cerro Azul, Valle de Cañete. Temporada de 1984. University of Michigan. Ann Arbor. EE.UU.

1986 Informe Anual de las excavaciones en Cerro Azul, valle de Cañete. Temporada de 1985. University of Michigan. Ann Arbor. EE.UU.

MARCUS, Joyce; Ramiro MATOS y María ROSTWOROWSKI

1985 «Arquitectura Inca de Cerro Azul, valle de Cañete». Revista del Museo Nacional. Tomo 47: 125-138. Lima.

MATOS, Ramiro

1994 Pumpu. Centro Administrativo Inka de la Puna de Junín. Lima. Perú Editores.

MENZEL, Dorothy

1971 «Estudios arqueológicos en los valles de Ica, Pisco, Chincha y Cañete». Arqueología y Sociedad. № 6. Lima: Museo de Arqueología y Etnología de la Universidad Nacional Mayor de San Marcos.

MENZEL, Dorothy \& John ROWE

1966 «The role of Chincha in late pre-spanish Peru». Nawpa Pacha. № 4. California: Berkeley.

MIDDENDORF, Ernest

1973 [1894] Perú. Observaciones y estudios del país y sus habitantes durante una permanencia de 25 años. Lima: UNMSM.

MORRIS, Craig

1973 «Establecimientos estatales en el Tawantinsuyu: una estrategia de urbanismo obligado». Revista del Museo Nacional. Tomo XXXIX: 127-141. Lima.

1974 «Huánuco Viejo: An Inca Administrative Center» En: Lamberg-Karlovsky y J. Sabloff (ed.). The Rise And Fall of Civilizations: Modern Archaeological Approaches to Ancient Cultures.. Cummins Publishing, Menlo Park. pp: 191-208.

1978 «Huánuco Pampa: Nuevas evidencias sobre el urbanismo Inca». Revista del Museo Nacional. Tomo XLIV: 139-152. Lima

1981 «Tecnología y organización inca del almacenamiento de víveres en la sierra». En: H. Lechtman y A. Soldi (compiladores). La Tecnología en el Mundo Andino: Subsistencia y Mensuración: 327-375. Universidad Nacional Autónoma de México, México, D.F. 
1999 «La arquitectura del Tahuantinsuyo». Los Incas: Arte y Símbolos. Banco de Crédito del Perú. Colección Arte y Tesoros del Perú: 1-59. Lima.

PEREIRA, H.D.

1993 Las qollqas incaicas de Cotapachi-Quillacollo. Museo Arqueológico de la Universidad San Simón. Cochabamba, Bolivia.

PROTZEN, Jean-Pierre

2008 Arquitectura y Construcción Incas en Ollantaytambo. Lima. PUCP Editores. Traducción Rafael Valdez y Sandra Téllez.

RAMÍREZ, Favio

2007 «Ocupaciones prehispánicas tardías en el complejo arqueológico de Cerro Azul». Bitácora de Cañete. Año 1, № 1: 25-32.

RAVINES, Rogger

1978 «Agricultura y riego». Tecnología Andina: 93-106. I.E.P. Lima- Perú.

RUALES, Mario

2000 «Investigaciones en Cerro del Oro, Valle de Cañete». Boletín de Arqueología PUCP. № 4: 359-399. Lima.

ROSTWOROWSKI, María

1980 «Guarco y Lunahuaná. Dos señoríos prehispánicos de la costa sur-central del Perú». Revista del Museo Nacional. Tomo XLIV: 153-214. Lima.

2004 Costa Peruana Prehispánica. Lima: I.E.P.

SANTILLANA, Idilio

1984 «La Centinela: Un asentamiento Inka - Chincha. Rasgos arquitectónicos estatales y locales». Arqueología y Sociedad. № 10: 13-32. Lima: Museo de Arqueología y Etnología de la Universidad Nacional Mayor de San Marcos.

SILVA-SANTISTEBAN, Fernando

1990 «Tecnología Agraria en el Antiguo Perú». El Mundo Andino - De la caza a las Tecnologías Agropecuarias. Universidad de Lima. Facultad de Ciencias Humanas.

STUMER, Louis

1971 «Informe preliminar sobre el recorrido del valle de Cañete». Arqueología y Sociedad. № 5: 23-35. Lima: Museo de Arqueología y Etnología de la Universidad Nacional Mayor de San Marcos.

TANTALEÁN, Henry

2011 «Cochahuasi: Un Palacio Inca en el Valle Medio del Río Mala». Revista Inkallaqta N 1: 7-22

TOPIC, Jhon y Coreen Chriswell

1992 Inka Storage Systems. University of Oklahoma Press. Norman and London.

TOWLE, Margaret

1961 The Ethnobotany of Precolumbian Peru. Aldine Publishing Company. Chicago.

VALDEZ, Lidio y Ernesto VALDEZ

2000 «Los Sistemas de Almacenamiento Inka de Tinyaq, Ayacucho, Perú». Boletín del IFEA. Tomo 29. Número 1: 13-27

VEGA-CENTENO

2011 «San Marcos, Huagil y Huaca Daris: Tres Sitios Inca de la Huaranca de Pacarán». Revista Haucaypata. $\mathrm{N}^{\circ}$ 3: 61-65.

WILLIAMS, Carlos y Manuel MERINO

1974 Inventario, catastro y delimitación del patrimonio arqueológico del valle de Cañete. Tomos I y II. Lima: Instituto Nacional de Cultura.

WALLACE, Dwight

1967 «Early Horizon Ceramics in the Cañete Valley of Peru». Ñawpa Pacha. Año 1: 35-39. Institute of Andean Studies, Berkeley, C.A. 